\title{
Forbs Rather Than Grasses as Key Factors Affecting Succession of Abandoned Fields - A Case Study from a Subalpine Region of the Eastern Tibet Plateau
}

\author{
Wenjin Li ${ }^{1,}{ }^{*}$, , Jinhua Li ${ }^{1, \dagger}$, Rulan Zhang ${ }^{1}$, Shuangshuang Liu ${ }^{1}$, Huakun Zhou ${ }^{2}$, Buqing Yao ${ }^{2}$, \\ Meiling Guo" ${ }^{2}$, Fangping Wang ${ }^{2}$ \\ ${ }^{1}$ State Key Laboratory of Grassland Agroecosystems, School of Life Sciences, Lanzhou University, Lanzhou, China \\ ${ }^{2}$ Key Laboratory of Restoration Ecology of Cold Area in Qinghai Province, Northwest Institute of Plateau Biology, Chinese Academy of \\ Sciences, Xining, China
}

\section{Email address:}

wenjinli@163.com (Wenjin Li), liwj@1zu.edu.cn (Wenjin Li), jinhuali@1zu.edu.cn (Jinhua Li)

${ }^{*}$ Corresponding author

†These authors contributed equally to this work and should be considered co-first authors

\section{To cite this article:}

Wenjin Li, Jinhua Li, Rulan Zhang, Shuangshuang Liu, Huakun Zhou, Buqing Yao, Meiling Guo, Fangping Wang. Forbs Rather Than Grasses as Key Factors Affecting Succession of Abandoned Fields - A Case Study from a Subalpine Region of the Eastern Tibet Plateau. Earth Sciences. Vol. 6, No. 5, 2017, pp. 80-87. doi: 10.11648/j.earth.20170605.14

Received: July 28, 2017; Accepted: August 10, 2017; Published: September 8, 2017

\begin{abstract}
An old-field chronosequence in the subalpine region of the Tibetan Plateau were used as a model system to test a hypothesis that forbs drive pathways of successional trajectories in earlier stages of succession and grasses drive the development of vegetation in later successional stages. All old fields were dominated by forbs, which accounted for $65-85 \%$ of species richness and abundance. Species richness and total plant abundance significantly increased with time since abandonment. This is in disagreement with 'humped-back model'. Although no consistent changes in seed size in the different functional groups found over time, however, there was a significant decline for the forbs, legumes, and annuals, except for the 1 -year old field. In this species-rich subalpine ecosystem, forbs rather than grasses and sedges were identified as key factors affecting community structure and plant assemblages, whenever in the earlier successional stages or in the later successional stages. These indicated that grassland managers and policy makers should recognize potential role of forbs in biodiversity conservation and ecosystem functioning.
\end{abstract}

Keywords: Forb Dominance, Chronosequence, Old-Field Succession, Shifts in Plant Community Composition, Plant Functional Groups, Subalpine Meadow, Tibet Plateau

\section{Introduction}

Old-field succession is often seed limited and plant community assembly can be controlled by soil seed bank, and seed dispersal [1, 2]. Many ecological restorations made many efforts by seeding [3-5] to accelerate the restoration of native vegetation or create semi-natural communities on degraded agricultural fields [6]. However, if cultivation intensity has been low, or in cases where old fields are small and placed within a regional vegetation dominated by native plant communities, there may remain a soil seed bank and dispersal from the surrounding vegetation might be high [7]. Under these conditions, spontaneous colonization processes can have the potential to be sufficient to restore degraded ecosystems [810]. A common observation in grasslands restoration worldwide is that large changes occur in plant community structure, dynamics, and function during succession [11], and that late successional plant communities are dominated by one to three grass species [12], which often account for more than $60 \%$ of the total plant cover in temperate ecosystems [13, 14]. The majority of the diversity is comprised of sub-dominants forbs and legumes which account often for less than $5 \%$ of the total plant cover [15]. In contrast to temperate ecosystems, many alpine types of grassland are dominated not only in species number, but also in abundance and biomass by forb 
species [16-18]. Therefore, predictions based on temperate vegetation succession may not be [19] valid for alpine ecosystems because they are characterized by harsh conditions, a short growing season, low productivity, and only episodic seed production [20]. This leads to slow plant growth rates and a slow recovery after disturbances [21-24]. These conditions may also lead to multiple different vegetation development pathways as a result of different initial circumstances [25], slow rates of changes, and infrequent establishment of new species. However, this slow recovery does not always occur and some studies have shown fast succession in alpine ecosystems [16].

In subalpine and alpine meadows of the Qinghai-Tibetan Plateau, previous studies of soil seed bank have shown that the abandoned agricultural fields have abundant soil seed banks $[26,27]$ and the soil seed bank can play a significant role in initial stages of succession, but not throughout the entire process [28]. In contrast, restoration of less-disturbed, later succession stage and natural meadows does not rely on seed banks, but is driven by seed dispersal from the surrounding vegetation and after initial establishment by vegetative reproduction [29, 30]. Clonal spread is the dominant mode of reproduction for many alpine plant species [29]. The establishment of seed is often episodic and only occurs in particularly favorable years, whereas clonal reproduction occurs continuously [31]. However, only a few studies on spontaneous secondary succession of old-fields in alpine ecosystems exist [32, 33]. Studies conducted in temperate grasslands suggest that small-seeded species with high seed production are good colonists but poor competitors. In contrast, large seeded species are good competitors but have low dispersal and are poor colonists [11]. Larger seed sizes are more common for late-successional species and have been shown to be advantageous for germination and establishment under shaded conditions and beneath litter layer.

Here succession dynamics were studied in an old-field chronosequence of $1,3,5,15$ and 30 yrs of abandonment on the eastern of the Tibet plateau. Changes in species richness and composition were analyzed in order to address the following questions: (i) How species richness and species abundances in the different functional groups change during succession (ii) How the index of species seed size in the different functional groups change during succession?

In our ecosystem, which is characterized by small disturbed fields with many clonal plant species, we hypothesize that (1) a weighted index of seed size increases over successional time; (2) forbs drive successional trajectories in earlier stages of succession and grasses drive the development of vegetation in later successional stages; (3) the vegetation restoration may also be fast and within a timescale of decades even with spontaneous succession without seed additions [6, 34, 35].

\section{Study Area}

A chronosequence of abandoned fields was established at the Research Station of Alpine Meadow and Wetland Ecosystems of Lanzhou University in the eastern part of the
Qing- Hai Tibetan Plateau, China (N34 55', E102 $\left.{ }^{\circ} 53^{\prime}\right)$ in 2003. This region has an elevation of 2,900-3,000 m. The annual mean temperature is $3.2^{\circ} \mathrm{C}$. The mean annual precipitation from 2000 to 2008 was $540 \mathrm{~mm}$, with $85 \%$ of the precipitation during the growing season from June through September [33]. The soil classified as a sub-alpine meadow soil. Many parts of the subalpine meadow in Hezuo were used for agriculture before the 1960s. Afterwards the government has aimed to restore those intensively used agricultural meadows towards a more natural species-rich meadow [29]. The agricultural practices in this region are a rain-fed oat (Avena sativa) - fallow - rape (Brassica napus) rotation [17].

\section{Materials and Methods}

\subsection{Sampling and Species Survey}

Here we used space-for-time substitutions approach and the time since abandonment as an indicator of the successional gradient [36]. In this study these fields were set aside from agriculture in 2002, 2000, 1998, 1988 and 1973. In addition, A natural, never-cultivated meadow was used as a control site. Here abandonment is defined as the cessation of agricultural practice such as ploughing [37]. The Hezuo Municipal Archives and personal interviews with landowners and managers were consulted to determine the age of abandonment of each site in 2003. All fields size were 0.1 ha approximately, which were at least $300 \mathrm{~m}$ apart, located within an area of $10 \mathrm{~km}^{2}$, and had the same south facing orientation with a slope of $15^{\circ}-25^{\circ}$. All fields were fenced to exclude large domestic herbivores (mainly sheep and cattle) in 1998 because the Chinese government implemented the cropland conversion to forest and grassland projects in 1998. All fields were surrounded by a mixture of natural never-cultivated grazed meadows and other abandoned fields. Within each field, $10(50 \times 50 \mathrm{~cm})$ permanent sampling plots were placed using a systematic sampling design along two $20 \mathrm{~m}$ transects with $10 \mathrm{~m}$ interval. Plots in each field were $3.5 \mathrm{~m}$ apart and about $5 \mathrm{~m}$ from the edge. We sampled annually in permanent plots at the peak of the growing season in August from 2003 to 2008 (2005, no sampling due to the others field work). Plants were identified to species. Species richness is the total number of species presents within each plot and plant abundances were estimated as the total number of stem individual present within each plot. For clonal plants, we counted apparent clusters of stems as an individual (a ramet in most cases). We cut all aboveground biomass, sorted it by species and recorded the weight of each plant species after drying to constant weight at $80^{\circ} \mathrm{C}$. To examine the changes in the different functional groups during succession, plants recorded in your study were classified into four functional groups: grasses and sedges, legumes and forbs (included all other species except for grasses, sedges and legumes), as is often done in grassland studies [38, 39].

Seed mass (SM) 


$$
\mathrm{SM}_{i}=\left(\sum \mathrm{p}_{i} \mathrm{Sz}_{i}\right) / \mathrm{N}
$$

Where SM is seed mass of species $i$; $p_{i}$ is the proportion of individuals of species $\mathrm{i}$ in the plot; $\mathrm{Sz}$ is the weight of 100 seeds of species i from the previous paper [40]; $\mathrm{N}$ is the number of all plant individuals in the plot.

Seed mass of functional groups is the sum of seed mass of same functional group species in the plot.

\subsection{Analysis}

Statistical analysis was conducted with SPSS for Windows 18.0. We performed a test (e.g. Levene) for homoscedasticity of variance, and if necessary, transform the data. Differences in all variables between a natural never-cultivated meadow and old fields were examined using one-way ANOVA (ns $\mathrm{P}>0.05 ; * \mathrm{P}<0.05 ; * * \mathrm{P}<0.01 ; * * * \mathrm{P}<0.001)$ and letters represent significant differences from post hoc Tukey tests $(\mathrm{P}<0.05)$. To avoid effects of pseudo-replicates (the sites of different successional age were not independently replicated, but only 10 replicates within each site were studied), all data represent mean value $(\mathrm{n}=10, \pm 1 \mathrm{~S}$. E for each field) from 2003 year to 2008 year.

\section{Results}

\subsection{Species Richness and Abundance in the Different Functional Groups During Succession}

Over a period of 6 years, in total we encountered a total of 205 species from 29 plant families, 94 genera, consisting of 170 forbs, 20 grasses, 5 sedges and 10 legumes. All fields were dominated by forbs, which accounted for $65-85 \%$ of species richness and abundance. The forbs richness and abundance also increased faster than the other functional groups. The perennials relative to the annuals accounted for $70-83 \%$ of species richness and abundance in all fields, and increased relatively faster than the annuals (Figure 1 and 2). Species richness and plant abundance in the perennial forbs were increasing quickly during the succession and the maximum value was found at the control site. The others functional groups did not varied strongly along the succession compared with the perennial forbs. Although there were significant increases in the species richness and plant abundance along the secondary succession, the total species richness and plant abundance was lower significantly at the different old fields sites than the control site (Figure 1 and 2). Thus, perennial forbs dominated both the early and late successional communities, and the grasses and sedges increased over time, but did not dominate in any of fields.
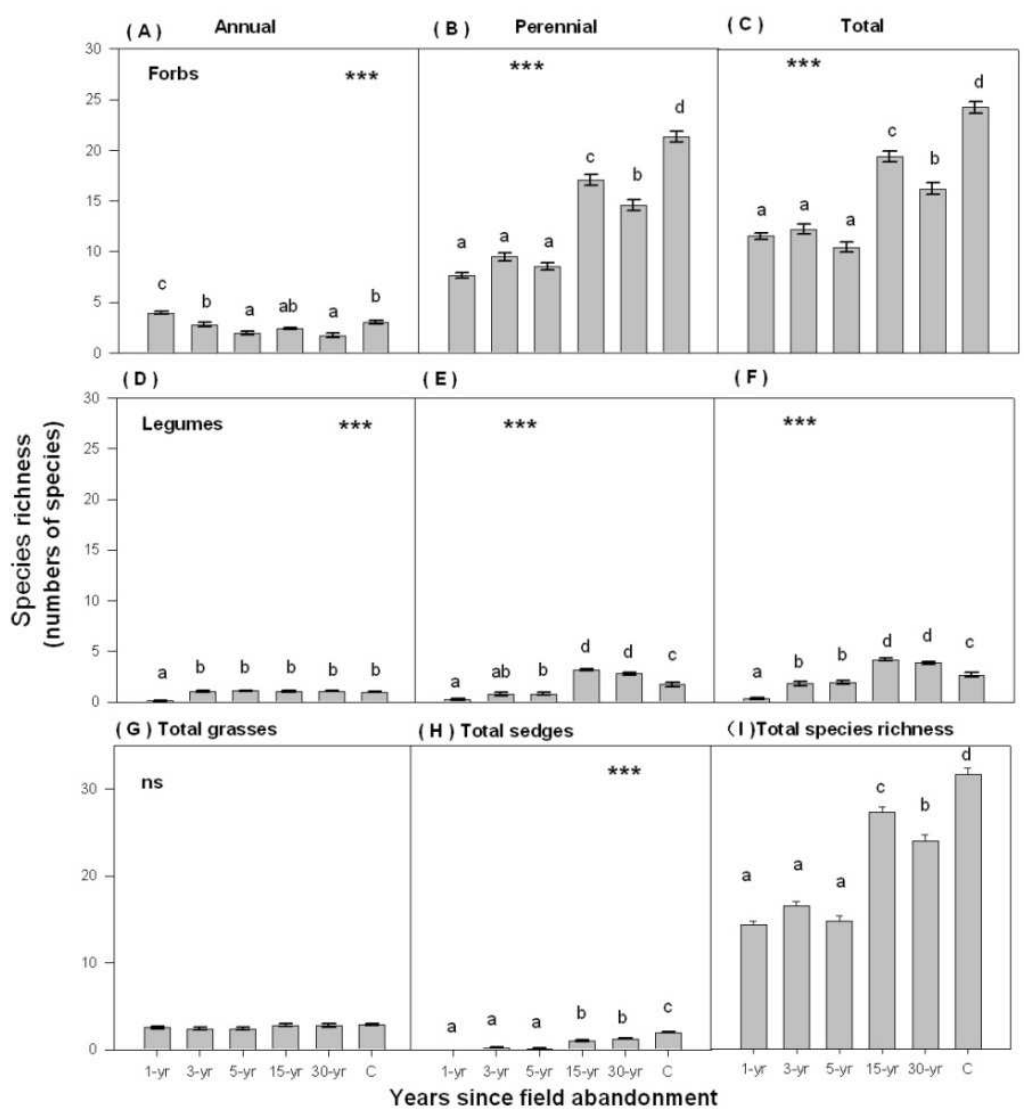

Figure 1. Changes in species richness of different life forms in different functional groups in the successive years since field abandonment and a natural, never-cultivated meadow as a control site (c). (A) annual forbs richness; (B) perennial forbs richness; (C) total forbs richness; (D) annual legumes richness; (E) perennial legumes richness; (F) total legumes richness; $(G)$ total graminoid richness; $(H)$ total sedges richness and (I) total species. Data represent mean $(n=10, \pm 1$ S. E for each field) from 2003 to 2008. All variables were examined using one-way ANOVA (ns - no significant P $>0.05$; $* P<0.05 ; * * P<0.01 ; * * * P<0.001)$ and letters represent significant differences from post hoc Tukey tests $(P<0.056)$. 


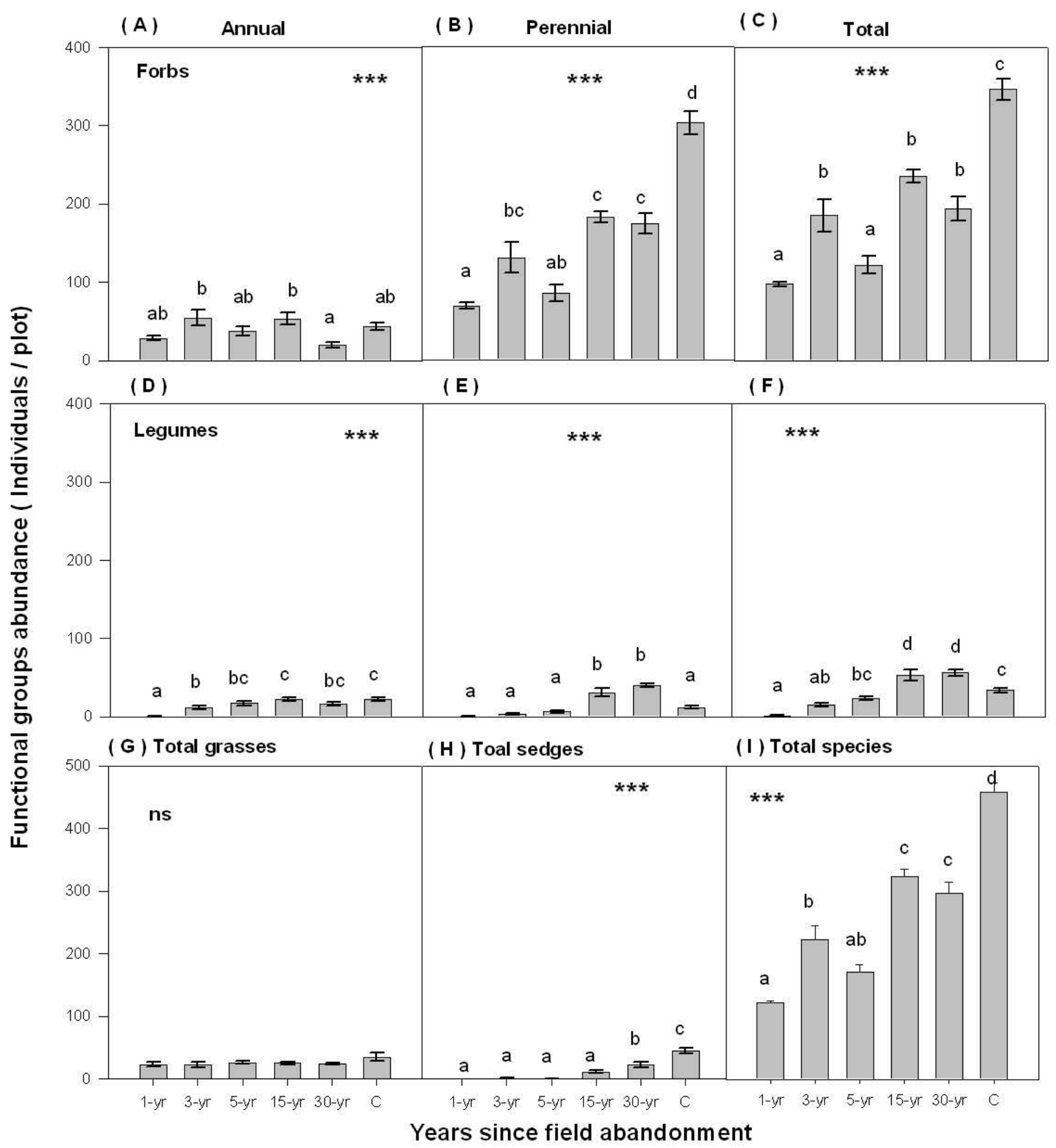

Figure 2. Changes in abundance of different life forms in the different functional groups in the successive years since field abandonment and a natural nevercultivated meadow as a control site (c). (A) annual forbs abundance; (B) perennial forbs abundance; (C) total forbs abundance; (D) annual legumes abundance; (E) perennial legumes abundance; $(F)$ total legumes abundance; $(G)$ total graminoid abundance and $(H)$ total sedges abundance and ( $I)$ total species. Data represent mean ( $=10, \pm 1$ S. E for each field) from 2003 to 2008. All variables were examined using one-way ANOVA (ns - no significant $P>0.05 ; * P<0.05 ; * * P<0.01 ; * * P<0.001)$ and letters represent significant differences from post hoc Tukey tests $(P<0.05)$.

\subsection{Seed Size Index in the Different Functional Groups During Succession}

No consistent changes in seed size index SM in the different functional groups were found over time. However, there was a significant decline in the forbs (annual and perennial) and annual legumes. The perennial legumes showed a humpshaped pattern. Interestingly, the sedges did show a consistent increase in SM index over time. Compared to all the old fields, SM index within the natural and never-cultivated meadow was the lowest (Figure 3). 


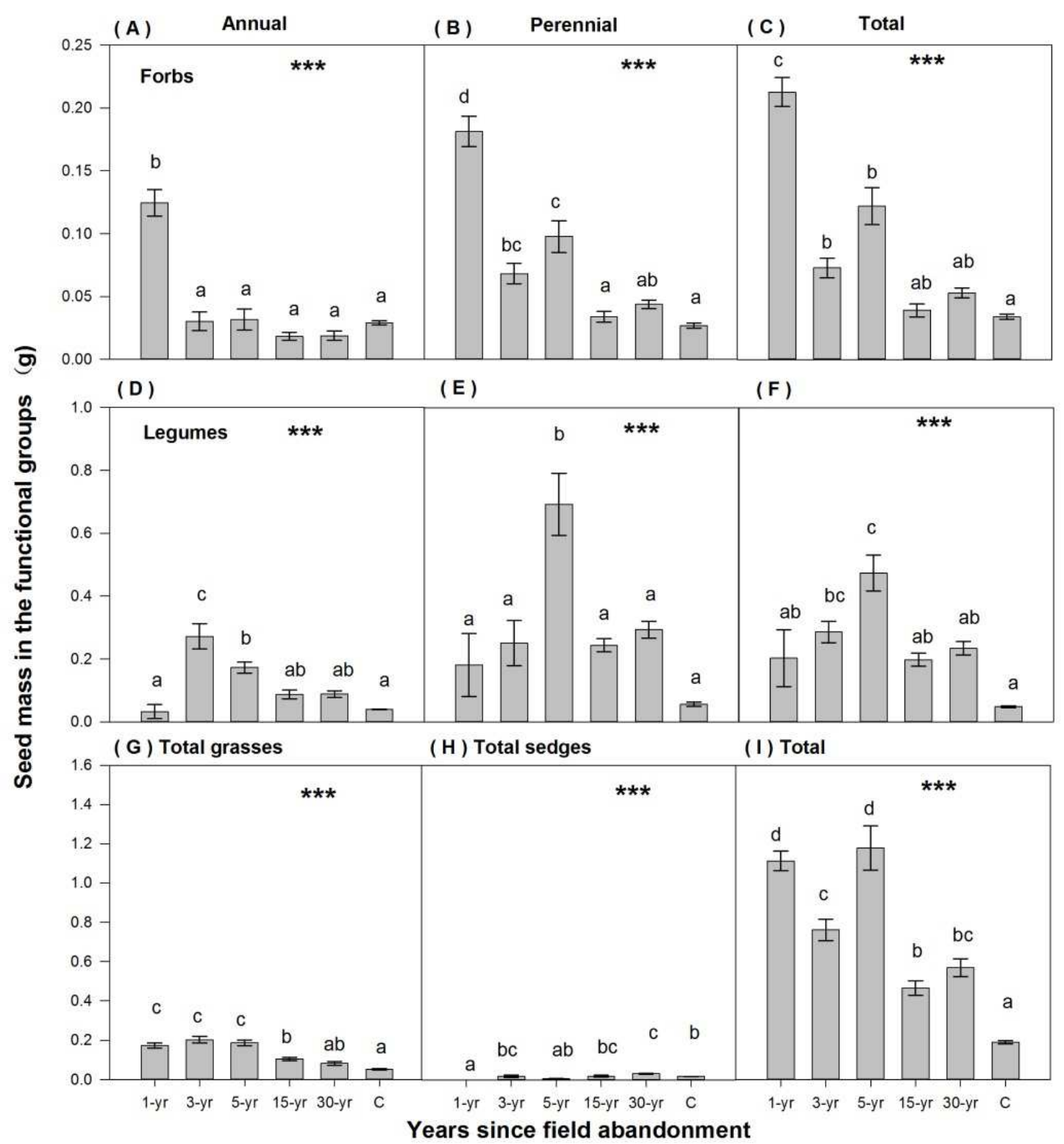

Figure 3. Changes in seed mass of different life forms in the different functional groups in the successive years since field abandonment and a natural nevercultivated meadow as a control site (c). (A) annual forbs; (B) perennial forbs; (C) total forbs; (D) for annual legumes; (E) perennial legumes; (F) total legumes; (G) total grasses; (H) total sedges and (I) entire community. Data represent mean ( $n=10, \pm 1$ S. E for each field) from 2003 to 2008 (not include 2005). All variables were examined using one-way ANOVA ( $n$ s - no significant $P>0.05 ; * P<0.05 ; * * P<0.01 ; * * P<0.001$ ) and letters represent significant differences from post hoc Tukey tests $(P<0.05)$.

\section{Discussion}

Our findings are consistent with most of the literature [4143] claimed a significant increase in the total species richness, plant abundance during succession. Species richness increased quickly during the first decade of abandonment and the maximum total richness was found at 18 years following abandonment, with decreasing species richness after that age. Our findings also indicate that with the increase in fallow years, the greatest changes take place in plant communities' structure. The perennials increased relatively faster than the annuals over time, while most of the annuals showed a decreasing trend or a non-significant change. This suggests that even in harsh climates, the vegetation successional pattern follows the commonly observed pattern of early dominance by annuals, then an increase in abundance of biennials, and, finally, perennials replacing other life forms and dominating late successional vegetation [44-48]. The finding also showed that that forb diversity increased faster than the other functional groups over time, and the forbs dominate species richness, abundance and aboveground biomass in all fields, including the natural never-cultivated meadow. This is consistent with a recent study of Arctic vegetation dynamics [49], which investigated temporal changes in the relative abundance of different growth forms over $5 \mathrm{kyr}$ time intervals and has revealed that forbs (non-graminoid herbaceous vascular plants) dominated Arctic vegetation. These findings question the predominance of a Late Quaternary graminoid-dominated 
Arctic steppe [49]. The few other studies in grasslands have also shown that in the absence of shrubs, plant community is dominated by forb species [16-18]. This is in contrast to most of the temperate ecosystem studies, in which late successional plant communities are dominated by grass species $[12,13,50]$.

In contrast to most successional studies, in which seed size increases over time [11], we found generally declining seed size over successional time. The exceptions to this general pattern were the legume functional group and the annual plant species. Our data suggests that seed dispersal influenced by seed size is not a key factor driving succession in the subalpine ecosystem. Previous studies of succession of degraded, overgrazed meadows in the subalpine and alpine region of the Qinghai-Tibetan Plateau have shown that secondary succession is driven by abundant soil seed banks [28]. In contrast, succession of abandoned agricultural fields which have reduced their soil seed bank, are driven by seed dispersal from the surrounding vegetation and vegetative reproduction [29, 30]. After establishment, clonal spread is the dominant reproductive pathway for many alpine or subalpine plant species [29]. We hypothesize that seed dispersal is rapid, regardless of seed size, because these relatively small abandoned fields are located in a matrix of native vegetation. On the other hand, late succession stages are dominated by forbs and sedges, and clonal reproduction may be driving their abundance increase.

The early stages of succession, up to an abandonment age of 6 years, show fast species turnover and rapid change in species composition, combined with rapid increases in plant abundance and aboveground biomass in our system, with no seed additions, similar to many other successional studies [6, $34,35]$. However, there were significant differences in species richness and abundance between the 30-years-old field and the never-cultivated meadow. The most pronounced differences are higher legume abundance in the old fields, and higher sedge abundance in the control field. This suggests that the subalpine ecosystem recovery by succession under harsh conditions over 30 years does not completely restore the original vegetation, and may result in a different alternative stable vegetation state. This is supported by the species turnover rate, following 15 years of succession, in which both the immigration rate and the extinction rate decline and converge, resulting in a stable vegetation structure. This also may be caused by depleted soil fertility and less available nutrient in the later succession, due to the harsh environment [17, 38], resulting in an increased importance of the nitrogen-fixing legume functional group. Soil fertility might require a much longer time to restore. Sedges mainly increase in abundance through clonal reproduction, and may only have episodic establishment in this harsh climate with a short growing season, low productivity, and episodic seed production [20]. Sedge establishment might also be limited by a replacement of other functional groups, especially the perennial forbs, and this community might stay at a different alternative stable state, typified by higher forb and lower sedge dominance.
A few studies in similar high altitude ecosystems have shown that the regeneration of vegetation can be much faster [16], however, most studies have shown slow recovery of vegetation after disturbances, similar to what we observed [22-24].

\section{Conclusion}

Taken together, in this subalpine ecosystem, forbs are the most important functional group driving the plant diversity and ecosystem productivity. Plant communities can recover plant diversity and ecosystem functioning of old fields without seed additions within a timescale of decades in the eastern Tibet Plateau. However, it is unclear if these old fields reach a different alternative stable vegetation state characterized by higher legume and lower sedge abundance, if soil fertility requires a much longer time to be restored, and if a decrease in soil fertility causes the increase in legume abundance and decrease in sedge abundance. However, in contrast with most herbaceous vegetation, these meadows are not "grasslands", as grasses comprise less than $20 \%$ of a total plant species richness, abundance and biomass. Forbs, as a dominant vegetation group in meadow vegetation, have not been given much attention, but in these alpine ecosystems, forbs play a vital role in succession and ecosystem function. Therefore, these suggest that land managers and policymakers need to recognize forb species richness in grassland classifications [51] and study the potential role of forbs in biodiversity conservation and ecosystem functioning such as productivity and nutrient cycling.

\section{Acknowledgements}

This work was supported by National Natural Science Foundation of China (31470480, 11575072, 31600336) and National key research and development project (No.2016YFC0501901) and Qinghai innovation platform construction project (2017-ZJ-Y20). We would like to thank the staffs of Research Station of Alpine Meadow and Wetland Ecosystems of Lanzhou University and the undergraduate students for their help in field investigation.

\section{Conflict of Interest Statement}

All the authors do not have any possible conflicts of interest.

\section{References}

[1] Kahmen, S.; Poschlod, P., 2008, Does germination success differ with respect to seed mass and germination season? Experimental testing of plant functional trait responses to grassland management. Annals of Botany 101, 541-548.

[2] Cousins, S. A. O.; Aggemyr, E., 2008, The influence of field shape, area and surrounding landscape an plant species richness in grazed ex-fields. Biological Conservation 141, 126-135. 
[3] Coulson, S. J.; Bullock, J. M.; Stevenson, M. J.; Pywell, R. F., 2001, Colonization of grassland by sown species: dispersal versus microsite limitation in responses to management. Journal of Applied Ecology 38, 204-216.

[4] Pywell, R. F.; Bullock, J. M.; Hopkins, A.; Walker, K. J.; Sparks, T. H.; Burke, M. J. W.; Peel, S., 2002, Restoration of species-rich grassland on arable land: assessing the limiting processes using a multi-site experiment. Journal of Applied Ecology 39, 294-309.

[5] Standish, R. J.; Cramer, V. A.; Wild, S. L.; Hobbs, R. J., 2007, Seed dispersal and recruitment limitation are barriers to native recolonization of old-fields in western Australia. Journal of Applied Ecology 44, 435-445.

[6] Fagan, K. C.; Pywell, R. F.; Bullock, J. M.; Marrs, R. H., 2008, Do restored calcareous grasslands on former arable fields resemble ancient targets? The effect of time, methods and environment on outcomes. Journal of Applied Ecology 45, 1293-1303.

[7] Cramer, V. A.; Hobbs, R. J.; Standish, R. J., 2008, What's new about old fileds? Land abandonment and ecosystem assembly. Trends in Ecology \& Evolution 23, 104-112.

[8] Ruprecht, E., 2005, Secondary succession in old-fields in the Transylvanian Lowland (Romania). Preslia 77, 145-157.

[9] Torok, P.; Matus, G.; Papp, M.; Tothmeresz, B., 2008, Secondary succession in overgrazed Pannonian sandy grasslands. Preslia 80, 73-85.

[10] Prach, K.; Hobbs, R. J., 2008, Spontaneous succession versus technical reclamation in the restoration of disturbed sites. Restoration Ecology 16, 363-366.

[11] Rees, M.; Condit, R.; Crawley, M.; Pacala, S.; Tilman, D., 2001, Long-term studies of vegetation dynamics. Science 293, 650-655.

[12] Freeman, C. C., The flora of Konza Prairie: a historical review and contemporary patterns. In Grassland dynamics: long-term ecological research in tallgrass prairies, Knapp, A. K., Ed. Oxford Univ. Press: 1998; pp 69-80.

[13] Miles, E. K.; Knops, J. M. H., 2009, Grassland compositional change in relation to the identity of the dominant matrixforming species. Plant Ecology \& Diversity 2, 265-275.

[14] Miles, E. K.; Knops, J. M. H., 2009, Shifting dominance from native $\mathrm{C}-4$ to non-native $\mathrm{C}-3$ grasses: relationships to community diversity. Oikos 118, 1844-1853.

[15] Collins, S. L.; Glenn, S. M., 1991, Importance of spatial and temporal dynamics in species regional abundance and distribution. Ecology 72, 654-664.

[16] Sarmiento, L.; Llambi, L. D.; Escalona, A.; Marquez, N., 2003, Vegetation patterns, regeneration rates and divergence in an old-field succession of the high tropical Andes. Plant Ecology 166, 63-74.

[17] Wang, G. L.; Liu, G. B.; Xu, M. X., 2009, Above- and belowground dynamics of plant community succession following abandonment of farmland on the Loess Plateau, China (vol 316, pg 227, 2009). Plant and Soil 322, 343-343.

[18] Hudson, J. M. G.; Henry, G. H. R., 2009, Increased plant biomass in a High Arctic heath community from 1981 to 2008. Ecology 90, 2657-2663.
[19] Lamb, E. G.; Kennedy, N.; Siciliano, S. D., 2011, Effects of plant species richness and evenness on soil microbial community diversity and function. Plant and Soil 338, 483495.

[20] Chambers, J. C., 1995, Disturbance, life history strategies, and seed fates in alpine herbfield communities. American Journal of Botany 82, 421-433.

[21] Janzen, D., 1973, Rate of regeneration after tropical high elevation fire. Biotropica 5, 117-122.

[22] Aplet, G. H.; Vitousek, P. M., 1994, An age-altitude matrix analysis of Hawaiian rain-forest succession. Journal of Ecology 82, 137-147.

[23] Hofstede, R. G. M.; Modragon, M. X.; Rocha, C. M., 1995, Biomassof grazed, burned and undisturbed paramo grasslands, Colombia. Aboveground vegetation. Artic and Alpine Research 27, 1-12.

[24] Aplet, G. H.; Flint, H. R.; Vitousek, P. M., 1998, Ecosystem development on Hawaiian lava flows: biomass and species composition. Journal of Vegetation Science 9, 17-26.

[25] Urbanska, K. M., 1997, Restoration ecology of alpine and artic areas: are the classical concepts of niche and succession directly applicable? Opera Botanica 132, 189-200.

[26] Deng, Z. F., 2003, Dynamic analysis of seed rain and seed bank in Kobresia pygmaea meadow. Chinese Journal. Applied. Environment. Biology 9, 7-1.

[27] Shang, Z. H., 2006, Soil seed banks of degraded alpine meadow grassland in headwater region of the Yellow River: quantities and dynamic of seed germination. Chinese Journal Applied. Environment. Biology. 12, 313-317.

[28] Wu, G. L.; Du, G. Z., 2007, Germination is related to seed mass in grasses (Poaceae) of the eastern Qinghai-Tibetan Plateau, China. Nordic Journal of Botany 25, 361-365.

[29] Ma, M. J.; Du, G. Z.; Zhou, X. H., 2009, Role of the Soil Seed Bank during Succession in a Subalpine Meadow on the Tibetan Plateau. Arctic Antarctic and Alpine Research 41, 469-477.

[30] Ma, M. J.; Zhou, X. H.; Du, G. Z., 2010, Role of soil seed bank along a disturbance gradient in an alpine meadow on the Tibet plateau. Flora 205, 128-134.

[31] Weppler, T.; Stoll, P.; Stocklin, J., 2006, The relative importance of sexual and clonal reproduction for population growth in the long-lived alpine plant Geum reptans. Journal of Ecology 94, 869-879.

[32] Rikhari, H. C.; Negi, G. C. S.; Ram, J.; Singh, S. P., 1993, Human-Induced Secondary Succession in an Alpine Meadow of Central Himalaya, India. Arctic and Alpine Research 25, 8-14.

[33] Li, W.; Li, J.; Liu, S.; Zhang, R.; Qi, W.; Zhang, R.; Knops, J. M. H.; Lu, J., 2017, Magnitude of Species Diversity Effect on Aboveground Plant Biomass Increases Through Successional Time of Abandoned Farmlands on the Eastern Tibetan Plateau of China. Land Degradation \& Development 28, 370-378.

[34] Chabrerie, O.; Laval, K.; Puget, P.; Desaire, S.; Alard, D., 2003, Relationship between plant and soil microbial communities along a successional gradient in a chalk grassland in northwestern France. Applied Soil Ecology 24, 43-56. 
[35] Alard, D.; Chabrerie, O.; Dutoit, T.; Roche, P.; Langlois, E., 2005, Patterns of secondary succession in calcareous grasslands: can we distinguish the influence of former land uses from present vegetation data? Basic and Applied Ecology $6,161-173$.

[36] Bonet, A.; Pausas, J. G., 2004, Species richness and cover along a 60 -year chronosequence in old-fields of southeastern Spain. Plant Ecology 174, 257-270.

[37] Bonet, A., 2004, Secondary succession of semi-arid Mediterranean old-fields in south-eastern Spain: insights for conservation and restoration of degraded lands. Journal of Arid Environments 56, 213-233.

[38] Li, W. J.; Li, J. H.; Lu, J. F.; Zhang, R. Y.; Wang, G., 2010, Legume-grass species influence plant productivity and soil nitrogen during grassland succession in the eastern Tibet Plateau. Applied Soil Ecology 44, 164-169.

[39] Šmilauer, P.; Šmilauerová, M., 2013, Asymmetric relationship between grasses and forbs: results from a field experiment under nutrient limitation. Grass and Forage Science 68, 186198

[40] Bu, H. Y.; Chen, X. L.; Xu, X. L.; Liu, K.; Jia, P.; Du, G. Z., 2007, Seed mass and germination in an alpine meadow on the eastern Tsinghai-Tibet plateau. Plant Ecology 191, 127-149.

[41] Baniya, C. B.; Solhoy, T.; Vetaas, O. R., 2009, Temporal changes in species diversity and composition in abandoned fields in a trans-Himalayan landscape, Nepal. Plant Ecology 201, 383-399.

[42] El-Sheikh, M. A., 2005, Plant succession on abandoned fields after 25 years of shifting cultivation in Assuit, Egypt. Journal of Arid Environments 61, 461-481.

[43] Kassi, N. J. K.; Decocq, G., 2008, Successional patterns of plant species and community diversity in a semi-deciduous tropical forest under shifting cultivation. Journal of Vegetation Science 19, 809-U12.
[44] Grime, J. P., Plant strategies and vegetation processes. Wiley: Chichester., 1979.

[45] Burrows, C. J., Processes of vegetation change. Unwin Hyman: London., 1990.

[46] Myster, R. W.; Pickett, S. T. A., 1994, A Comparison of Rate of Succession over $18 \mathrm{Yr}$ in 10 Contrasting Old Fields. Ecology 75, 387-392.

[47] Foster, B. L.; Tilman, D., 2000, Dynamic and static views of succession: Testing the descriptive power of the chronosequence approach. Plant Ecology 146, 1-10.

[48] Anderson, K. J., 2007, Temporal patterns in rates of community change during succession. American Naturalist $169,780-793$.

[49] Willerslev, E.; Davison, J.; Moora, M.; Zobel, M.; Coissac, E.; Edwards, M. E.; Lorenzen, E. D.; Vestergard, M.; Gussarova, G.; Haile, J.; Craine, J.; Gielly, L.; Boessenkool, S.; Epp, L. S.; Pearman, P. B.; Cheddadi, R.; Murray, D.; Brathen, K. A.; Yoccoz, N.; Binney, H.; Cruaud, C.; Wincker, P.; Goslar, T.; Alsos, I. G.; Bellemain, E.; Brysting, A. K.; Elven, R.; Sonstebo, J. H.; Murton, J.; Sher, A.; Rasmussen, M.; Ronn, R.; Mourier, T.; Cooper, A.; Austin, J.; Moller, P.; Froese, D.; Zazula, G.; Pompanon, F.; Rioux, D.; Niderkorn, V.; Tikhonov, A.; Savvinov, G.; Roberts, R. G.; MacPhee, R. D. E.; Gilbert, M. T. P.; Kjaer, K. H.; Orlando, L.; Brochmann, C.; Taberlet, P., 2014, Fifty thousand years of Arctic vegetation and megafaunal diet. Nature 506, 47-51.

[50] Galvanek, D.; Leps, J., 2008, Changes of species richness pattern in mountain grasslands: abandonment versus restoration. Biodiversity and Conservation 17, 3241-3253.

[51] Pokorny, M. L.; Sheley, R. L.; Svejear, T. J.; Engel, R. E., 2004, Plant species diversity in a grassland plant community: evidence for forbs as a critical management consideration. Western North American Naturalist, 219-230. 